\title{
Evidencia serológica de infección por herpesvirus caprino tipo 1 en cabras en México
}

Montserrat E. García-Hernández a

Rosa E. Sarmiento-Silva ${ }^{a}$

Liliana M. Valdés-Vázquez ${ }^{\text {a }}$

Laura Cobos-Marín ${ }^{\text {a* }}$

a Universidad Nacional Autónoma de México. Facultad de Medicina Veterinaria y Zootecnia. Departamento de Microbiología e Inmunología,. Av. Universidad 3000, Circuito Exterior S/N col. Universidad Nacional Autónoma de México, CU. Ciudad Universitaria Delegación Coyoacán 04510, Ciudad de México. México.

*Autor de correspondencia: laura.cobosmarin@gmail.com

\section{Resumen:}

En México no se han realizado estudios serológicos sobre herpesvirus caprino tipo 1 con el propósito de saber el estado de la infección por CpHV-1. Se llevó a cabo un análisis serológico para determinar la presencia de anticuerpos contra el virus usando un ELISA de bloqueo comercial para detección de anticuerpos contra la glicoproteína B $(\mathrm{gB})$ y glicoproteína $\mathrm{E}$ ( $\mathrm{gE}$ ) del herpesvirus bovino tipo 1, de acuerdo con la prueba diagnóstica que se utiliza de forma rutinaria. De un total de 838 animales analizados, 123 (14.68\%) resultaron positivos a la prueba de ELISA. En los estados de Puebla, Morelos, Nuevo León, Ciudad de México, Guanajuato y Querétaro se encontró evidencia serológica de la presencia del CpHV-1 en cabras. Este reporte es el primer estudio que señala la presencia de anticuerpos contra herpesvirus caprino en cabras en México.

Palabras clave: Caprino, Herpesvirus, México, Cabras, Seroprevalencia, ELISA.

Recibido: 02/03/2018

Aceptado: 04/04/2018 
Los virus pertenecientes a la familia Herpesviridae están ampliamente distribuidos en la naturaleza y afectan un gran número de especies animales ${ }^{(1,2)}$. Uno de los principales herpesvirus que afectan la producción caprina es el Herpesvirus Caprino tipo 1 (CpHV1) el cual provoca pérdidas económicas significativas en las unidades productoras caprinas. El CpHV-1 tiene un distribución mundial con altas seroprevalencias especialmente en la cuenca Mediterránea ${ }^{(3-8)}$. Este virus infecta células epiteliales in vivo e in vitro, produciendo una infección citolítica y estableciendo una infección latente en los ganglios sacros y trigéminos. El estado latente es mantenido durante la vida del animal y puede ser reactivado bajo condiciones de estrés. El virus provoca abortos, muerte neonatal, vulvovaginitis y balanopostitis en adultos, así como enfermedad sistémica en cabritos $^{(2,6)}$.

El CpHV1 es un virus envuelto que contiene un gran número de glicoproteínas, entre las cuales la glicoproteína $\mathrm{B}(\mathrm{gB})$, glicoproteína $\mathrm{C}(\mathrm{gC})$ y glicoproteína $\mathrm{D}(\mathrm{gD})$ son las más abundantes ${ }^{(9)}$. El análisis filogenético de secuencias nucleotídicas y de aminoácidos de $\mathrm{gB}$ y gD, revelan que el $\mathrm{CpHV}-1$ es el virus más distante entre los alfaherpesvirus que afectan a rumiantes como son: herpesvirus bovino tipo 1 (BoHV-1), herpesvirus bovino tipo 5 (BoHV-5), herpesvirus cérvido tipo 1 y 2 (CvHV-1, CvHV-2), y herpesvirus de alce $(\mathrm{RanHV}-1)^{(10)}$.

Basados en la secuencia completa de la $\mathrm{gB}$, la cual es la más conservada entre herpesvirus, el porcentaje de identidad entre CpHV-1 y BoHV-1 es $78.5 \%{ }^{(9)}$. Debido a que hay una homología entre el herpesvirus bovino y el virus caprino, y a la falta de anticuerpos comerciales disponibles para $\mathrm{CpHV}-1$ para realizar su diagnóstico serológico, se han utilizado kits comerciales para detección de anticuerpos contra $\mathrm{gB}$ de $\operatorname{IBR}^{(8,11)}$.

En México no se han realizado estudios seroepidemiológicos sobre esta enfermedad. Sin embargo, Candanosa et $a^{(12)}$ reportan la posible presencia de la enfermedad en un brote sospechoso ocurrido en un hato en el estado de Querétaro en 2008.

Con el propósito de conocer el estado epidemiológico de la infección en cabras del país, se realizó un estudio serológico en cabras de ocho estados usando un ELISA comercial para detección de anticuerpos contra la gB de BoHV-1. Para distinguir entre una infección provocada por el virus bovino, se utilizó una prueba de detección de anticuerpos contra la gE de BoHV-1 debido a la diferencia antigénica entre ambos virus.

Se analizaron 838 sueros de los siguientes estados: Querétaro, Puebla, Guanajuato, Ciudad de México, Veracruz, Nuevo León y Morelos. Se utilizaron dos pruebas comerciales de ELISA de bloqueo: Herdchek Anti-IBR gB (Idexx, Germany) y Herdchek Anti-IBR gE (Idexx, Germany). Las muestras se trabajaron de acuerdo con las instrucciones del fabricante ${ }^{(3)}$.

Se detectó la presencia de anticuerpos contra CpHV-1 en los estados de Puebla, Morelos, Nuevo León, Ciudad de México y Guanajuato. De un total de 838 muestras analizadas, 
se detectaron anticuerpos contra gB en 123 (14.68\%). Dentro de estos 123 sueros positivos, 93 se analizaron para la detección de gE. Únicamente dos animales resultaron positivos y dos sospechosos. En los estados de Puebla, Nuevo León y el Distrito Federal se observó un porcentaje del 33.33, 32.73 y $27.34 \%$ de positividad, mientras que en Querétaro ésta fue del $10 \%$ y Veracruz resultó negativo (Cuadro 1). La serología positiva a gB de BoHV-1 en $14.68 \%$ de las muestras analizadas junto con la falta de positividad en la mayoría de las muestras en la prueba confirmatoria de detección de gE (99.9\%), sugieren que estos animales pudieron estar en contacto con $\mathrm{CpHV}-1$ de acuerdo con lo previamente reportado ${ }^{(1,3,7)}$.

Cuadro 1: Resultados de las pruebas de ELISA realizadas por entidad federativa

\begin{tabular}{|c|c|c|c|c|c|}
\hline \multirow[b]{2}{*}{ Estado } & \multirow[b]{2}{*}{$\begin{array}{c}\text { Muestras } \\
\text { analizadas }\end{array}$} & \multicolumn{2}{|c|}{ ELISA gB } & \multicolumn{2}{|c|}{ ELISA gE } \\
\hline & & Positivos & $(\%)$ & Positivos & Sospechosos \\
\hline Querétaro & 427 & 43 & 10.07 & & \\
\hline Puebla & 51 & 17 & 33.33 & 1 & 1 \\
\hline Guanajuato & 106 & 3 & 2.83 & & \\
\hline Ciudad de México & 139 & 38 & 27.34 & 0 & \\
\hline Veracruz & 52 & 0 & 0.00 & & \\
\hline Nuevo León & 55 & 18 & 32.73 & 1 & 1 \\
\hline Morelos & 8 & 4 & 50.00 & 0 & 0 \\
\hline Total & 838 & 123 & 14.68 & 2 & 2 \\
\hline
\end{tabular}

Ros et $a l^{(9)}$, reportan que la prueba de ELISA de bloqueo para anti-gB mostró una sensibilidad del $93 \%$ en cabras experimentalmente infectadas con $\mathrm{CpHV}-1$, por lo que este método se considera efectivo para la detección de infección por herpesvirus caprino por la antigenicidad cruzada para $\mathrm{gB}^{(9)}$.

Debido a que la infección natural por BoHV-1 en cabras ha sido reportada en pocas ocasiones $^{(11)}$, la positividad a la prueba de $\mathrm{gE}$ en dos de los animales analizados podría deberse a un alto nivel de inmunización por un contacto reciente. Es notable que ambas muestras positivas a $\mathrm{gE}$ tuvieron niveles de bloqueo mayores a $90 \%$ en la prueba para gB. Otra razón para esta positividad podría ser cierto grado de antigenicidad cruzada entre CpHv-1 gE y BoHV-1 gE debido a epítopos compartidos entre ambos, como lo reportado en el virus de pseudorabia ${ }^{(13)}$.

Este es el primer estudio en México que indica la presencia de anticuerpos contra herpesvirus en cabras. Los resultados sugieren que el herpesvirus caprino tipo 1 se encuentra en México, lo que indica que en casos de aborto en cabras el CpHv-1 debería considerarse como un diagnóstico presuntivo. En el caso del estado de Querétaro, a pesar de que el porcentaje de muestras positivas fue de $10.47 \%$, debe señalarse que algunas de estas muestras provenían de un hato con lesiones sospechosas a $\mathrm{CpHV}-1$ que habían sido 
reportadas con anterioridad ${ }^{(12)}$. Además, las muestras de tejidos fueron encontradas positivas a CpHV-1 por inmunohistoquímica usando anticuerpos monoclonales. Estos resultados sugieren que el virus circula en esta región de México.

\section{Agradecimientos}

Al Centro de Enseñanza, Investigación y Extensión en Producción Animal del Altiplano (CEIEPAA), a María Grisel Anaya Santillán y Hugo César Sánchez Rivera por las facilidades prestadas. Este trabajo se realizó con fondos de la Dirección General de Apoyos al Personal Académico (DGAPA) de la Universidad Nacional Autónoma de México (UNAM), PAPIIT IN228511-3.

Este estudio se realizó con la autorización de los propietarios de los animales.

\section{Literatura citada:}

1. Thiry J, Keuser V, Muylkens B, Meurens F, Gogev S, Vanderplasschen A, et al. Ruminant alphaherpesviruses related to bovine herpesvirus 1. Vet Res 2006;37(2):169-190.

2. Tempesta M, Pratelli A, Greco G, Martella V, Buonavoglia C. Detection of caprine herpesvirus 1 in sacral ganglia of latently infected goats by PCR. J Clin Microbiol 1999;37(5):1598-1599.

3. Thiry J, Saegerman C, Chartier C, Mercier P, Keuser V, Thiry E. Serological evidence of caprine herpesvirus 1 infection in Mediterranean France. Vet Microbiol 2008;128(4):261-268.

4. Keuser V, Espejo-Serrano J, Schynts F, Georgin JP, Thiry E. Isolation of caprine herpesvirus type 1 in Spain. Vet Rec 2004;154(13):395-399.

5. Koptopoulos G, Papanastasopoulou M, Papadopoulos O, Ludwig H. The epizootiology of caprine herpesvirus (BHV-6) infections in goat populations in Greece. Comp Immunol Microbiol Infect Dis 1988;11(3):199-205.

6. Saito JK, Gribble DH, Berrios PE, Knight HD, Mc Kercher DG. A new herpesvirus isolate from goats: Preliminary report. Am J Vet Res 1974;35:847-848.

7. Mettler F, Engels M, Wild P, Bivetti A. Herpesvirus-Infektion bei Zicklein in der Schweiz. Arch Thierheilkd 1979; 655-662.

8. Keuser V, Schynts F, Detry B, Collard A, Robert B, Vanderplasschen A, et al. Improved antigenic methods for differential diagnosis of bovine, caprine, and 
cervine Alphaherpesviruses related to bovine herpesvirus 1. J Clin Microbiol 2004;42(3):1228-1235.

9. Ros C, Belák S. Characterization of the glycoprotein B gene from ruminant alphaherpesviruses. Virus Genes 2002;24(2):99-105.

10. Ros C, Belák S. Studies of genetic relationships between bovine, caprine, cervine, and rangiferine alphaherpesviruses and improved molecular methods for virus detection and identification. J Clin Microbiol 1999;37(5):1247-1253.

11. Marinaro M, Bellacicco AL, Tarsitano E, Camero M, Colao V, Tempesta M, et al. Detection of Caprine herpesvirus 1-specific antibodies in goat sera using an enzymelinked immunosorbent assay and serum neutralization test. J Vet Diagn Invest 2010;22(2):245-248.

12. Candanosa AE, Sierra GM, Sánchez AC, Salas GG, Méndez AB, Cobos LM, et al. Vulvovaginitis y balanopostitis pustular sugerente a herpesvirus caprino-1 en cabras (Querétaro México). Vet Mex 2011;42(3):233-243.

13. Jacobs L, Kimman TG. Epitope-specific antibody response against glycoprotein $\mathrm{E}$ of pseudorabies virus. Clin Diagn Lab Immunol 1994;1(5):500-505. 